\title{
Prediction of surgically induced astigmatism in manual and femtosecond laser-assisted clear corneal incisions
}

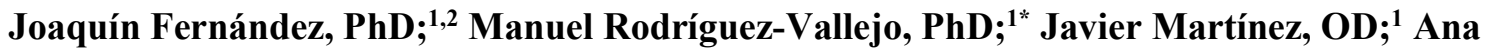 \\ Tauste, PhD $;^{1}$ David P Piñero, PhD $^{3,4}$
}

\footnotetext{
${ }^{1}$ Department of Ophthalmology (Qvision), Vithas Virgen del Mar Hospital, 04120, Almería, Spain

${ }^{2}$ Department of Ophthalmology, Torrecárdenas Hospital Complex, 04009, Almería, Spain

${ }^{3}$ Department of Optics, Pharmacology and Anatomy, University of Alicante, Alicante, Spain

${ }^{4}$ Department of Ophthalmology (OFTALMAR), Vithas Medimar International Hospital, Alicante, Spain

\section{"Corresponding author: manuelrodriguezid@qvision.es (Tel +34686500808)}

Mailing address: Departamento de Oftalmología (Qvision), Hospital Vithas Virgen del Mar, Carr. el Mami a Viator, km 1, 04120 Almería (España)

Number of Figures: 3 Number of Tables: 2 
Prediction of surgically induced astigmatism

1

2

3

4

5

6

7

8

\section{2) Abstract}

Purpose: To assess the surgically induced astigmatism (SIA) with femtosecond laser-assisted and manual temporal clear corneal incisions and to evaluate the performance of a model for prediction of the SIA based on the preoperative corneal astigmatism.

Methods: Clinical data of 104 right eyes and 104 left eyes undergoing cataract surgery, 52 with manual incisions and 52 with femtosecond laser-assisted incisions in each eye group, were extracted and revised retrospectively. In all cases, manual incisions were $2.2 \mathrm{~mm}$ width and femtosecond incisions were $2.5 \mathrm{~mm}$ width, both at temporal location. A predictive model of the SIA was obtained by means of simple linear regressions analyses.

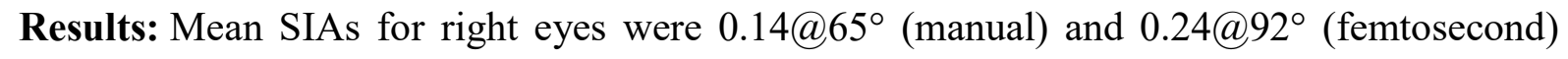
( $p>0.05)$ and for left eyes, $0.15 @ 101^{\circ}$ (manual) and 0.19@104 (femtosecond)(p>0.05). The orthogonal components of the SIA $\left(\mathrm{X}_{\mathrm{SIA}}, \mathrm{Y}_{\mathrm{SIA}}\right)$ were significantly correlated $(\mathrm{p}<0.05)$ with the preoperative orthogonal components of corneal astigmatism $\left(X_{\text {preop }}, Y_{\text {preop }}\right)(r=-0.29$ for $X$ and $\mathrm{r}=-0.1$ for $\mathrm{Y}$ ). The preoperative astigmatism explained $8 \%$ of variability of the $\mathrm{X}_{\mathrm{SIA}}$ and $3 \%$ of the variability of $\mathrm{Y}_{\text {SIA. The postoperative corneal astigmatism prediction was }}$ not improved by the SIA obtained from the model in comparison to the simple vector subtraction of the mean SIA.

Conclusions: Temporal incisions induce similar astigmatism either for manual or femtosecond procedures. This can be clinically negligible for being considered for toric intraocular lens calculation due to the great standard deviation in comparison to the mean. The usefulness of the prediction model should be confirmed in patients with high preoperative corneal astigmatism.

Keywords: Surgically induced astigmatism, clear corneal incisions, temporal, manual, femtosecond laser-assisted 
Prediction of surgically induced astigmatism

3

4

5

6

\section{3) Manuscript Text}

\section{a) Introduction.}

Surgically induced astigmatism (SIA) is defined as the difference between the postoperative and preoperative astigmatism and can be applied to either manifest refractive or corneal analysis.(1) The SIA induced by clear corneal incisions (CCIs) has been studied for years Temporal incisions have shown to induce less with-the-rule (WTR) astigmatism compared to the against-the-rule (ATR) astigmatism induced by superior incisions.(2,3) Likewise, the SIA has shown to increase with the incision width.(3-5) CCIs are considered the standard incisions in cataract surgery because of their advantages in terms of lower duration of the procedure, less incidence of complications, lower SIA,(6) and faster visual recovery.(7) However, these incisions created with a keratome are poorly reproducible, with particular conditions, such as gapes, misalignment, Descemet detachment and loss of coaptation.(8) CCIs created with femtosecond laser-assisted systems are more predictable, with less incidence of these particular features, $(9,10)$ and avoiding the disadvantages of wound leakage by keratome incisions.(7)

The results of the comparison of SIA for manual CCIs (M-CCIs) and femtosecond laserassisted CCIs (F-CCIs) has been previously reported. Mastropasqua et al.(11) compared biplanar F-CCIs of $2.8 \mathrm{~mm}$ width at $130^{\circ}$ versus $2.75 \mathrm{~mm}$ M-CCIs at the same location, reporting no significant differences in the mean SIA, but with lower varibility for the F-CCIs. Nagy et al(12) compared both methods but with $2.8-\mathrm{mm}$ incision widths over the steep meridian, reporting no significant differences in the magnitude of SIA but significant differences for the deviation of the SIA axis from the planned. More recently, Diakonis et al.(12) reported no differences for $2.5 \mathrm{~mm}$ width F-CCIs at $200^{\circ}$ or $20^{\circ}$ for right and left eyes, respectively, in comparison with M-CCIs for the same width and locations. All these previous studies agree that there are no significant differences between M-CCIs and F-CCIs 
1 in terms of SIA, but all the analyses were performed with data of alternating eyes between M-

2 CCIs and F-CCIs,(13) including one eye per patient(12) or including only right eyes.(11)

3 Any of the previous works have addressed the differences in SIA between left and right eyes

4 considering both techniques or have proposed a model for a better prediction of the SIA. The

5 main aim of this work was to assess the SIA for temporal M-CCIs and F-CCIs in a left-

6 handed surgeon. A secondary aim was to find a model for a better prediction of the SIA

7 beyond the mean.

b) Subjects and Methods

\section{Subjects}

11 This study was approved by the local ethics committee of research and was performed in adherence to the tenets of the Declaration of Helsinki. Data from 104 right eyes and 104 left eyes, 52 undergoing manual CCI (M-CCI) and 52 femtosecond laser-assisted CCI (F-CCI), operated on cataract surgery at Qvision (Department of Ophthalmology, Virgen del Mar Hospital) were extracted from our historic database. Left eyes and right eyes were enrolled with independence of the subject, and therefore some subjects might be included simultaneously in the right and left eyes groups. All eyes included in the analysis underwent a surgery without any kind of complication and no eye complications were reported during the follow-up period. Data recovered from the preoperative and 1 month follow-up visits included: keratometry, anterior chamber length (ACD) and axial length (AL) measured with the IOL Master 500 system (Carl Zeiss Meditec, Dublin, CA). 
Prediction of surgically induced astigmatism

\section{Surgical Procedure}

3 The same left-handed surgeon (JF) performed all the cataract surgeries with the Victus

4 femtosecond laser system and the Stellaris phaco machine (both from Bausch \& Lomb Inc,

5 Dornach, Germany).

6

\section{$7 \quad$ Clear corneal incisions}

8 F-CCIs were performed with the VICTUS platform (Bausch \& Lomb Inc, Dornach, 9 Germany). Three-plane incisions were programmed in the laser with the following settings: $10300 \mu \mathrm{m}$ of posterior depth and $80^{\circ}$ of side cut angle for plane $1,570 \mu \mathrm{m}$ of posterior depth for plane 2, and $900 \mu \mathrm{m}$ of posterior depth and $70^{\circ}$ of side cut angle for plane 3 . Main CCIs settings were of equal width $2.5 \mathrm{~mm}$, length $1.5 \mathrm{~mm}$, and offset from limbus approximately of $0.3 \mathrm{~mm}$, either for right and left eyes except for the location, at 170 degrees in the right eyes and at 10 degrees in the left eyes. Two-plane incisions were programmed for the paracentesis, $300 \mu \mathrm{m}$ of posterior depth and $80^{\circ}$ of side cut angle for plane 1 and $900 \mu \mathrm{m}$ of posterior depth and $40^{\circ}$ of side cut angle for plane 2 . Paracentesis incisions were $1 \mathrm{~mm}$ width, and were located at $80^{\circ}$ away from main CCIs, at $250^{\circ}$ in the right eyes and $90^{\circ}$ in the left eyes. Length and offset from the limbus for the paracentesis incision were $1.2 \mathrm{~mm}$ and 0.3 $\mathrm{mm}$, respectively.

Manual CCIs were performed with a keratome blade Laseredge Trapezoidal Knive $2.0 \mathrm{~mm}$ $2.2 \mathrm{~mm}$ angled (Bausch + Lomb Storz ${ }^{\circledR}$ Instruments). The location planned to be used by the surgeon was the same as in the F-CCIs method, either for left and right eyes, and were intended to follow a 2-step architecture. The paracentesis was also planned to be done in the same position described above with a sideport knife of $1.6 \mathrm{~mm}$ width (Bausch + Lomb Storz ${ }^{\circledR}$ Instruments). 
Prediction of surgically induced astigmatism

\section{Statistical Analysis}

3 The normality of data distributions of the variables included in the study was tested with the

4 Kolmogorov-Smirnov test. The Student t-test for independent samples was used for

5 comparisons with variables normally distributed, whereas the Mann-Whitney test was used

6 for variables non-normally distributed. Furthermore, correlations were also evaluated with the

7 Pearson or the Spearman's correlations coefficients depending if the correlated variables

8 followed or not a Normal distribution, respectively. A predictive model of the SIA was

9 constructed by means of simple linear regression analyses after confirming that the required

assumptions were accomplished, including the Durbin-Watson statistic for independence of observations, the homoscedasticity, and the normally distribution of the residuals. The SPSS version 20 (SPSS Inc, Chicago, Illinois, USA) was used for the statistical analysis. The Alpins vectorial method(14-16) was implemented in a Matlab library (R2009; MathWorks, Natick, MA) in order to compute the SIA and to perform the graphical representations.

c) Results

Descriptive preoperative data for the right and left eyes operated on using M-CCIs or F-CCIs are detailed in Table 1. No significant differences were found in age, anterior chamber depth and axial length between M-CCIs and F-CCIs groups, either for right and left eyes. Preoperative corneal astigmatism significantly only differed between groups in the orientation of the oblique component of the astigmatism decomposition ( $\left.\mathrm{Y}_{\text {preop }}\right)$ in the left eye $(p=0.04)$. No significant differences were found for the median magnitude of the preoperative astigmatism $\left(\mathrm{M}_{\text {preop }}\right)$ between M-CCIs and F-CCIs groups, either for right or left eyes. 
Prediction of surgically induced astigmatism

\section{SIA for M-CCIs and F-CCIs}

2 No significant differences were found between M-CCIs and F-CCIs, neither for right nor for left eyes, as detailed in Table 2 and Figure 1. Despite of the lack of significance, the SIA was slightly higher in the F-CCIs group for both eyes. Differences between eyes performed by the same technique were also evaluated, obtaining no significant differences $(p>0.05)$, neither in M-CCIs nor in F-CCIs. The only exception was found for the $\mathrm{Y}_{\text {SIA }}$ component in the M-CCIs method which was $0.11 \pm 0.37 \mathrm{D}$ for the right eyes and $-0.06 \pm 0.32 \mathrm{D}$ for the left eyes $(\mathrm{t}=$ 2.44, $\mathrm{p}=0.02$ ). These greater differences between eyes for the M-CCIs were also manifested in the resulting angle of the mean SIA, $65^{\circ}$ for right eyes versus $101^{\circ}$ for left eyes (see Table 2). The SIA for all the aggregated data (208 eyes) was also computed, resulting in a mean of $0.16 \mathrm{D}$ at $93^{\circ}$ and a median of $0.18 \mathrm{D}$ at $90^{\circ}$.

\section{Model for surgically induced astigmatism prediction}

As no significant differences were found between right and left eyes and among techniques, all data were combined in order to find a model for a better prediction of the SIA rather than the mean or median reported in table 2 . From the preoperative collected variables described on table 1, only the $\mathrm{X}_{\text {preop }}$ and $\mathrm{Y}_{\text {preop }}$ were significantly correlated with the $\mathrm{X}_{\mathrm{SIA}}(\mathrm{r}=-0.29, \mathrm{p}<$ $0.001)$ and $\mathrm{Y}_{\mathrm{SIA}}(\mathrm{r}=-0.10, \mathrm{p}=0.01)$, respectively (Figure 2). On the other hand, no significant correlations were found for age, ACD or AXL and the $\mathrm{X}_{S I A}$ or $\mathrm{Y}_{S I A}$ components $(\mathrm{p}>0.05)$. Therefore, only the preoperative astigmatism was considered in the prediction model based on linear regression analysis. Figure $2 \mathrm{~A}$ shows that the higher the preoperative ATR astigmatism, the higher was the WTR SIA, and the higher the preoperative WTR, the higher was the ATR SIA.

The linear regression analysis established that $X_{\text {preop }}$ could be predicted $\left(X_{S I A}, F=16.51\right.$, $\mathrm{p}<0.001$ ), with $\mathrm{X}_{\text {preop }}$ accounting for $8 \%$ of the explained variability in $\mathrm{X}_{\mathrm{SIA}}$. The regression equation was $\mathrm{X}_{S I A}=-0.15^{*} \mathrm{X}_{\text {preop }}-0.16$. On the other hand, the linear regression analysis also 
1 established that $Y_{\text {preop }}$ could be predicted $\left(Y_{S I A}, F=6.37, p<0.01\right)$, with $Y_{\text {preop }}$ accounting for 3\%

2 of the explained variability in $\mathrm{Y}_{\mathrm{SIA}}$. The regression equation was $\mathrm{Y}_{\mathrm{SIA}}=-0.12 * \mathrm{Y}_{\text {preop }}-0.004$.

After combination of both components, the SIA model resulted in:

$$
S I A=\sqrt{\left(-0.15 \mathrm{X}_{\text {preop }}-0.16\right)^{2}+\left(-0.12 \mathrm{Y}_{\text {preop }}-0.004\right)^{2}}
$$

Figure 3 shows the difference between the postoperative manifest astigmatism and the postoperative astigmatism predicted by the addition of the median SIA $\left(0.18 \mathrm{D} @ 90^{\circ}\right)$ (Figure $3 \mathrm{~A})$ or the postoperative astigmatism predicted by the addition of the SIA obtained from the model (Figure 3B). The coordinates of the center of Figure 3A were $\mathrm{x}: 0.02$ and $\mathrm{y}:-0.01$ and standard deviations SDx: 0.53 and SDy: 0.36). On the other hand, the coordinates of the center of Figure 3B were x: 0.004 and y: -0.006 and standard deviations SDx: 0.51 and SDy: 0.35 .

\section{d) Discussion}

This study showed that the SIA was not significantly different between M-CCIs and F-CCIs if incisions are programmed at temporal location. Our results are in complete agreement with all the previous studies. Diakonis et al.(13) reported lower SIA for M-CCIs (0.09 D) than for F-CCIs $(0.20 \mathrm{D})$, but without statistically significant differences among groups, using incisions located at $200^{\circ}$ for right eyes and $20^{\circ}$ for left eyes. Our results are very similar, with a mean between 0.14 D-0.15 D for M-CCIs and 0.19 D-0.24 D for F-CCIs, depending if the right or left eye was analyzed. Moreover, it is important to note that Diakonis et al used incision widths of $2.5 \mathrm{~mm}$ (for M-CCIs) and $2.4 \mathrm{~mm}$ (for F-CCIs), whereas we used $2.2 \mathrm{~mm}$ (for M-CCIs) and $2.5 \mathrm{~mm}$ (for F-CCIs) in our study. Mastropasqua et al(11) also reported the mean components $\mathrm{J}_{0}$ and $\mathrm{J}_{45}$, equivalent to the $\mathrm{X}$ and $\mathrm{Y}$ of our study but in Thibos notation,(17) for preoperative and postoperative astigmatism. Although SIA was not reported in the their study, we computed the SIA from their means obtaining $0.18 \mathrm{D}$ for F-CCIs and 
$10.27 \mathrm{D}$ for M-CCIs for locations of the incision at $130^{\circ}$ and incision width of $2.8 \mathrm{~mm}$. The

2 SIAs from our and the previous mentioned studies were lower than that reported by Nagy et

3 al,(12) which can be explained by the location of the main incision on the steep meridian

$4 \quad$ instead of the common temporal position in all eyes. Both Mastropasqua et al(11) and Nagy

5 et al(12) suggested greater variability in the angle for M-CCIs. We found that the angle of the

6 mean SIA was more oblique in the right eye with M-CCIs than in the left eye with M-CCIs or

7 in both eyes with F-CCIs. $\left(<15^{\circ}\right.$ for the vertical meridian $\left(90^{\circ}\right)$ possibly due to the left-handed

8 characteristics of the surgeon).

9 Correlations between $\mathrm{X}_{\mathrm{SIA}} / \mathrm{Y}_{\text {SIA }}$ and $\mathrm{X}_{\mathrm{PRE}} / \mathrm{Y}_{\text {PRE }}$ (Figure 2) suggest that there exists not only a greater magnitude of the SIA for higher preoperative astigmatisms but also that the SIA angle varies depending on the angle of the preoperative astigmatism. Therefore, if the eye has a high amount of preoperative ATR astigmatism, the SIA induced is WTR but if the eye has a high amount of preoperative WTR astigmatism, the SIA induced is ATR despite of conducting a temporal incision (Figure 2). This finding should be interpreted with caution because the $72 \%$ of our sample have a $\mathrm{X}_{\text {preop }}$ inside $\pm 1.00 \mathrm{D}$ and should be confirmed in the future with a greater sample of eyes with corneal astigmatism only above $1.00 \mathrm{D}$. Furthermore, despite the accomplishment of the assumptions to conduct a linear regression model for predicting the SIA, our model only explained $8 \%$ of variability of the $\mathrm{X}_{\text {SIA }}$ and $3 \%$ of the variability of $\mathrm{Y}_{\text {SIA. }}$ This may be attributed to several factors, including the small sample size containing astigmatism of more than $1.00 \mathrm{D}$ and significant differences in the mechanical properties of the corneas included in the study. A replication of the experiment must be done for higher amounts of preoperative corneal astigmatism. The Figure 3 shows that the postoperative astigmatism predicted with our model was almost equal to the predicted only considering the addition of the median SIA. Therefore, the model is not useful 
1 in low astigmatisms and its possible advantages should be confirmed for higher values of

2 preoperative corneal astigmatism.

3 The need of the SIA analysis in high corneal astigmatism has been previously pointed out by

4 other authors,(18) but few studies have addressed this issue because patients with high

5 corneal astigmatism are generally treated with toric intraocular lenses and the SIA is

6 generally evaluated without the separation of the corneal induced astigmatism from the

7 refractive analysis.(19-22) We only found the study of Visser et al(23) who reported the

8 distribution of corneal SIA in high astigmatism. Despite of having a similar mean SIA, it is

9 important to note that the standard deviation in the double plot vector analysis almost doubled

10 the obtained in our study with temporal incisions, especially for the $\mathrm{Y}_{\text {SIA. }}$

11 We aware that our research may have some limitations. First, the study was conducted considering the corneal power obtained from keratometry which is computed considering only the anterior corneal radius with a keratometric index approximation. It is well known that the corneal astigmatism obtained by this approximation can differ from the obtained considering the measure of both corneal surfaces and computing the total corneal refractive power by ray-tracing. $(24,25)$ To the best of our knowledge, only Klijn et al(26) evaluated the role of posterior cornea on the SIA, reporting that SIA of the posterior corneal surface after cataract surgery is of negligible clinical relevance. Future studies, similar to our work, should be performed in order to evidence the differences between SIA derived from keratometry or total corneal refractive power. Second, the incision size for M-CCIs was $0.3 \mathrm{~mm}$ less than for F-CCIs, the reason was a surgeon preference who usually performs the M-CCIs of $2.2 \mathrm{~mm}$ width but for the same size in F-CCIs the incision has greater sealability and more resistance for inserting the IOL are experimented. Therefore in the common practice the surgeon performs F-CCIs slightly higher than M-CCIs. Furthermore, we performed the study at 1 month of follow-up because as Chang et al(27) reported, the SIA is stabilized at 1 week 
1 postoperatively for $2.2 \mathrm{~mm}$ incisions and at 1 month for $2.75 \mathrm{~mm}$. However, long term

2 follow-up differences would be recommendable in future studies.

3 In conclusion, temporal incisions performed with manual keratome or femtosecond laser-

4 assisted lead to similar SIA. However, lower differences in the resulting SIA angle between

5 left and right eyes suggest that a higher precision in the location of the main and paracentesis

6 incisions is achieved with the femtosecond laser. In our opinion, from a clinical point of

7 view, the standard deviation of the mean SIA in comparison to the centroid value is too large

8 to consider it in the calculation of the postoperative corneal astigmatism for clinical purposes,

9 such as including this value in the calculators of toric intraocular lenses, especially 10 considering the steps in the dioptric power of commercial lenses and the dioptric manufacturing tolerance.(28) Furthermore, we found that even though temporal incisions lead on average to WTR astigmatism, the magnitude and orientation of the SIA might depend of the magnitude and orientation of the preoperative astigmatism, even leading to ATR astigmatism in eyes with previous high WTR astigmatism. This should be studied in the future considering only eyes with high preoperative astigmatism for which a prediction model such as the suggested in our study might have clinical application.

\section{4) Declaration of interest}

JF and MR-V have received personal fees from Bausch \& Lomb outside the submitted work. None of the other authors has a financial or proprietary interest in any material or method mentioned. 


\section{5) References}

1. Reinstein DZ, Archer TJ, Randleman JB. JRS Standard for Reporting Astigmatism Outcomes of Refractive Surgery. J Refract Surg. 2014; 30: 654-9.

2. Simşek S, Yaşar T, Demirok A, Cinal A, Yilmaz OF. Effect of superior and temporal clear corneal incisions on astigmatism after sutureless phacoemulsification. J Cataract Refract Surg. 1998; 24: $515-8$.

3. Nielsen PJ. Prospective evaluation of surgically induced astigmatism and astigmatic keratotomy effects of various self-sealing small incisions. J Cataract Refract Surg. 1995; 21: $43-8$.

4. Kohnen T, Dick B, Jacobi KW. Comparison of the induced astigmatism after temporal clear corneal tunnel incisions of different sizes. J Cataract Refract Surg. 1995; 21: 417-24.

5. Masket S, Wang L, Belani S. Induced astigmatism with 2.2- and 3.0-mm coaxial phacoemulsification incisions. J Refract Surg. 2009; 25: 21-4.

6. Borasio E, Mehta JS, Maurino V. Surgically induced astigmatism after phacoemulsification in eyes with mild to moderate corneal astigmatism. Temporal versus on-axis clear corneal incisions. J Cataract Refract Surg. 2006; 32: 565-72.

7. Al Mahmood A, Al-Swailem S, Behrens A. Clear corneal incision in cataract surgery. Middle East Afr J Ophthalmol. 2014; 21: 25-31.

8. Lyles GW, Cohen KL, Lam D. OCT-documented incision features and natural history of clear corneal incisions used for bimanual microincision cataract surgery. Cornea. 2011; 30: 681-6.

9. Takhtaev Y V, Nizametdinova YS, Shukhaev S V. The comparison of tunnel corneal incision performed with femtosecond laser and keratome. Ophthalmol J. 2016; 9: 5-13.

10. Grewal DS, Basti S. Comparison of morphologic features of clear corneal incisions created with a femtosecond laser or a keratome. J Cataract Refract Surg. 2014; 40: 521-30. 
Prediction of surgically induced astigmatism

11. Mastropasqua L, Toto L, Mastropasqua A, et al. Femtosecond laser versus manual clear corneal incision in cataract surgery. J Refract Surg. 2014; 30: 27-33.

12. Nagy ZZ, Dunai A, Kranitz K, et al. Evaluation of femtosecond laser-assisted and manual clear corneal incisions and their effect on surgically induced astigmatism and higher-order aberrations. J Refract Surg. 2014; 30: 522-5.

13. Diakonis VF, Yesilirmak N, Cabot F, et al. Comparison of surgically induced astigmatism between femtosecond laser and manual clear corneal incisions for cataract surgery. J Cataract Refract Surg. 2015; 41: 2075-80.

14. Alpins NA. A new method of analyzing vectors for changes in astigmatism. J. Cataract Refract. Surg. 1993; 19: 524-33.

15. Eydelman MB, Drum B, Holladay J, et al. Standardized analyses of correction of astigmatism by laser systems that reshape the cornea. J Refract Surg. 2006; 22: 81-95.

16. Næser K. Assessment and statistics of surgically induced astigmatism. Acta Ophthalmol. 2008; 86: 349.

17. Thibos LN, Wheeler W, Horner D. Power vectors: an application of Fourier analysis to the description and statistical analysis of refractive error. Optom Vis Sci. 1997; 74: 367-75.

18. Borasio E, Mehta JS, Maurino V. Torque and flattening effects of clear corneal temporal and on-axis incisions for phacoemulsification. J Cataract Refract Surg. 2006; 32: 2030-8.

19. Alió JL, Agdeppa MC, Pongo VC, El Kady B. Microincision cataract surgery with toric intraocular lens implantation for correcting moderate and high astigmatism: Pilot study. J Cataract Refract Surg. 2010; 36: 44-52.

20. Mendicute J, Irigoyen C, Aramberri J, Ondarra A, Montés-Micó R. Foldable toric intraocular lens for astigmatism correction in cataract patients. J Cataract Refract Surg. 2008; 34: 601-7.

21. Ninomiya Y, Minami K, Miyata K, et al. Toric intraocular lenses in eyes with with-the-rule, against-the-rule, and oblique astigmatism: One-year results. J Cataract Refract Surg. 2016; 42: $1431-40$. 
Prediction of surgically induced astigmatism

22. Lubiński W, Gronkowska-Serafin J, Podborączyńska-Jodko K. Clinical outcomes after cataract surgery with implantation of the Tecnis ZMB00 multifocal intraocular lens. Med Sci Monit. 2014; 20: 1220-6.

23. Visser N, Ruíz-Mesa R, Pastor F, Bauer NJ, Nuijts RM, Montés-Micó R. Cataract surgery with toric intraocular lens implantation in patients with high corneal astigmatism. J Cataract Refract Surg. 2011; 37: 1403-10.

24. Koch DD, Jenkins RB, Weikert MP, Yeu E, Wang L. Correcting astigmatism with toric intraocular lenses: Effect of posterior corneal astigmatism. J Cataract Refract Surg. 2013; 39: 1803-1809.

25. Reitblat O, Levy A, Kleinmann G, Abulafia A, Assia El. Effect of posterior corneal astigmatism on power calculation and alignment of toric intraocular lenses: Comparison of methodologies. J Cataract Refract Surg. 2016; 42: 217-25.

26. Klijn S, van der Sommen CM, Sicam VA, Reus NJ. Value of posterior keratometry in the assessment of surgically induced astigmatic change in cataract surgery. Acta Ophthalmol. 2016; 94: 494-8.

27. Chang SW, Su TY, Chen YL. Influence of ocular features and incision width on surgically induced astigmatism after cataract surgery. J Refract Surg. 2015; 31: 82-8.

28. ISO-11979-2. Ophthalmic implants - Intraocular lenses - Part 2: Optical properties and test methods. 2014. 


\section{6) Tables}

Table 1. Descriptive preoperative data for right and left eyes and differences among Manual Clear Corneal Incision (M-CCIs) and Femtosecond laser-assisted (F-CCIs). Mean \pm standard deviation are represented in the top row of each variable and median [interquartile range] in the bottom.

\begin{tabular}{|c|c|c|c|c|c|c|}
\hline & \multicolumn{2}{|c|}{ Right Eyes n=104 } & \multirow{2}{*}{$\begin{array}{c}\text { t-test }^{\mathrm{a}} \\
\text { U-Mann }\end{array}$} & \multicolumn{2}{|c|}{ Left Eyes $n=104$} & \multirow{2}{*}{$\begin{array}{c}\text { t-test }{ }^{\mathrm{a}} \\
\text { Mann-W }^{\mathrm{b}}\end{array}$} \\
\hline & M-CCls $(n=52)$ & $\mathrm{F}-\mathrm{CCls}(\mathrm{n}=52)$ & & M-CCls $(n=52)$ & F-CCls $(n=52)$ & \\
\hline \multirow[t]{2}{*}{ Age } & $69.04 \pm 9.18$ & $67.48 \pm 8.38$ & $z=-1.08$ & $64.60 \pm 9.45$ & $63.35 \pm 9.40$ & $z=-0.68$ \\
\hline & 70.5 [11] & 68 [15] & $p=0.28^{b}$ & 68 [14] & $63[18]$ & $p=0.497^{b}$ \\
\hline \multirow[t]{2}{*}{$A C D$} & $3.10 \pm 0.41$ & $3.05 \pm 0.38$ & $t=0.64$ & $3.11 \pm 0.41$ & $3.12 \pm 0.32$ & $t=-0.114$ \\
\hline & 3.16 [1.77] & $3.04[0.50]$ & $p=0.52^{a}$ & $3.14[0.74]$ & $3.08[0.47]$ & $p=0.91^{a}$ \\
\hline \multirow[t]{2}{*}{$A X L$} & $23.87 \pm 1.87$ & $23.82 \pm 1.69$ & $z=-0.124$ & $24.12 \pm 2.03$ & $23.70 \pm 1.60$ & $z=-1.304$ \\
\hline & $23.59[1.37]$ & 23.52 [1.85] & $p=0.90^{b}$ & 23.71 [1.90] & 23.37 [1.80] & $p=0.19^{b}$ \\
\hline \multirow[t]{2}{*}{$X_{\text {preop }}$} & $0.20 \pm 1.05$ & $0.06 \pm 0.93$ & $t=0.72$ & $-0.13 \pm 1.07$ & $-0.06 \pm 0.97$ & $t=-0.37$ \\
\hline & $0.21[1.25]$ & 0.03 [1.36] & $p=0.47^{a}$ & $-0.08[1.32]$ & $-0.03[1.43]$ & $p=0.71^{a}$ \\
\hline \multirow[t]{2}{*}{$Y_{\text {preop }}$} & $0.08 \pm 0.77$ & $0.03 \pm 0.59$ & $z=0.163$ & $0.11 \pm 0.54$ & $-0.11 \pm 0.51$ & $t=2.12$ \\
\hline & $0.00[0.61]$ & $0.00[0.50]$ & $p=0.87^{b}$ & $0.07[0.72]$ & $-0.1[0.67]$ & $p=0.04^{a}$ \\
\hline \multirow[t]{2}{*}{$M_{\text {preop }}$} & $1.07 \pm 0.76$ & $0.91 \pm 0.62$ & $z=-0.96$ & $0.99 \pm 0.69$ & $0.96 \pm 0.53$ & $z=0.41$ \\
\hline & $0.94[0.96]$ & $0.75[0.68]$ & $p=0.34^{b}$ & 0.80 [0.69] & $0.92[0.80]$ & $p=0.68^{b}$ \\
\hline
\end{tabular}

ACD: Anterior Chamber Depth; AXL: Axial Length; Xpreop: Horizontal component from the double-angle decomposition (positive $0^{\circ}$ and negative $90^{\circ}$ ) of the preoperative astigmatism; Ypreop: Vertical component from the double-angle decomposition (positive $45^{\circ}$ and negative $135^{\circ}$ ) of the preoperative astigmatism; $M_{\text {preop: }}$ : Absolute magnitude of the cylinder obtained from the mean and median preoperative astigmatism without considering the astigmatism orientation.

${ }^{a} t$-test of independent samples performed

${ }^{\mathrm{b}}$ Mann-Whitney test performed 
Table 2. SIA results for comparison between M-CCIs and F-CCIs.

\begin{tabular}{|c|c|c|c|}
\hline & $\mathrm{M}-\mathrm{CCls}$ & $\mathrm{F}-\mathrm{CCls}$ & t-test ${ }^{\mathrm{a}}, \mathrm{U}$-Mann ${ }^{\mathrm{b}}$ \\
\hline \multicolumn{4}{|l|}{ Right eyes } \\
\hline \multirow[t]{2}{*}{$X_{S I A}$} & $-0.09 \pm 0.45$ & $-0.23 \pm 0.59$ & $\mathrm{t}=-1.38, p=0.17^{\mathrm{a}}$ \\
\hline & $-0.07[0.56]$ & $-0.18[0.76]$ & \\
\hline \multirow[t]{2}{*}{$\mathrm{Y}_{\text {SIA }}$} & $0.11 \pm 0.37^{*}$ & $-0.02 \pm 0.39$ & $\mathrm{t}=-1.66, p=0.1^{\mathrm{a}}$ \\
\hline & $0.11[0.40]$ & $-0.01[0.34]$ & \\
\hline \multirow[t]{2}{*}{$M_{S I A}$} & $0.49 \pm 0.35$ & $0.63 \pm 0.40$ & $z=-0.96, p=0.34^{b}$ \\
\hline & $0.40[0.32]$ & $0.56[0.42]$ & \\
\hline Mean SIA & $0.14 @ 65^{\circ}$ & $0.24 @ 92^{\circ}$ & \\
\hline Median SIA & $0.13 @ 60^{\circ}$ & $0.18 @ 91^{\circ}$ & \\
\hline \multicolumn{4}{|l|}{ Left eyes } \\
\hline \multirow[t]{2}{*}{$\mathrm{X}_{\mathrm{SIA}}$} & $-0.14 \pm 0.50$ & $-0.17 \pm 0.57$ & $\mathrm{t}=-0.29, p=0.77^{\mathrm{a}}$ \\
\hline & $-0.25[0.61]$ & $-0.30[0.65]$ & \\
\hline \multirow[t]{2}{*}{$Y_{S I A}$} & $-0.06 \pm 0.32 *$ & $-0.09 \pm 0.33$ & $\mathrm{t}=-0.48, p=0.64^{\mathrm{a}}$ \\
\hline & $-0.03[0.38]$ & $-0.09[0.30]$ & \\
\hline \multirow[t]{2}{*}{$M_{S I A}$} & $0.52 \pm 0.32$ & $0.59 \pm 0.34$ & $z=-0.41, p=0.68^{b}$ \\
\hline & $0.43[0.34]$ & $0.57[0.48]$ & \\
\hline Mean SIA & $0.15 @ 101^{\circ}$ & $0.19 @ 104^{\circ}$ & \\
\hline Median SIA & $0.25 @ 94^{\circ}$ & $0.31 @ 98^{\circ}$ & \\
\hline
\end{tabular}

$\mathrm{X}_{\mathrm{SIA}}$ : Horizontal component from the double-angle decomposition (positive $0^{\circ}$ and negative $90^{\circ}$ ) of the SIA; Y YIA: Vertical component from the double-angle decomposition (positive $0^{\circ}$ and negative $90^{\circ}$ ) of the SIA; M MIA: Absolute magnitude of the cylinder obtained from the mean and median SIA without considering the astigmatism orientation.

${ }^{a}$ t-test of independent samples performed

${ }^{\mathrm{b}}$ Mann-Whitney test performed 


\section{7) Figure Legends}

Figure 1. Double-angle plots for the SIA in (A) M-CCI of right eyes, (B) M-CCIs of left eyes,

(C) F-CCIs of right eyes and (D) F-CCI of left eyes. Sector steps corresponds to 0.5 diopter.
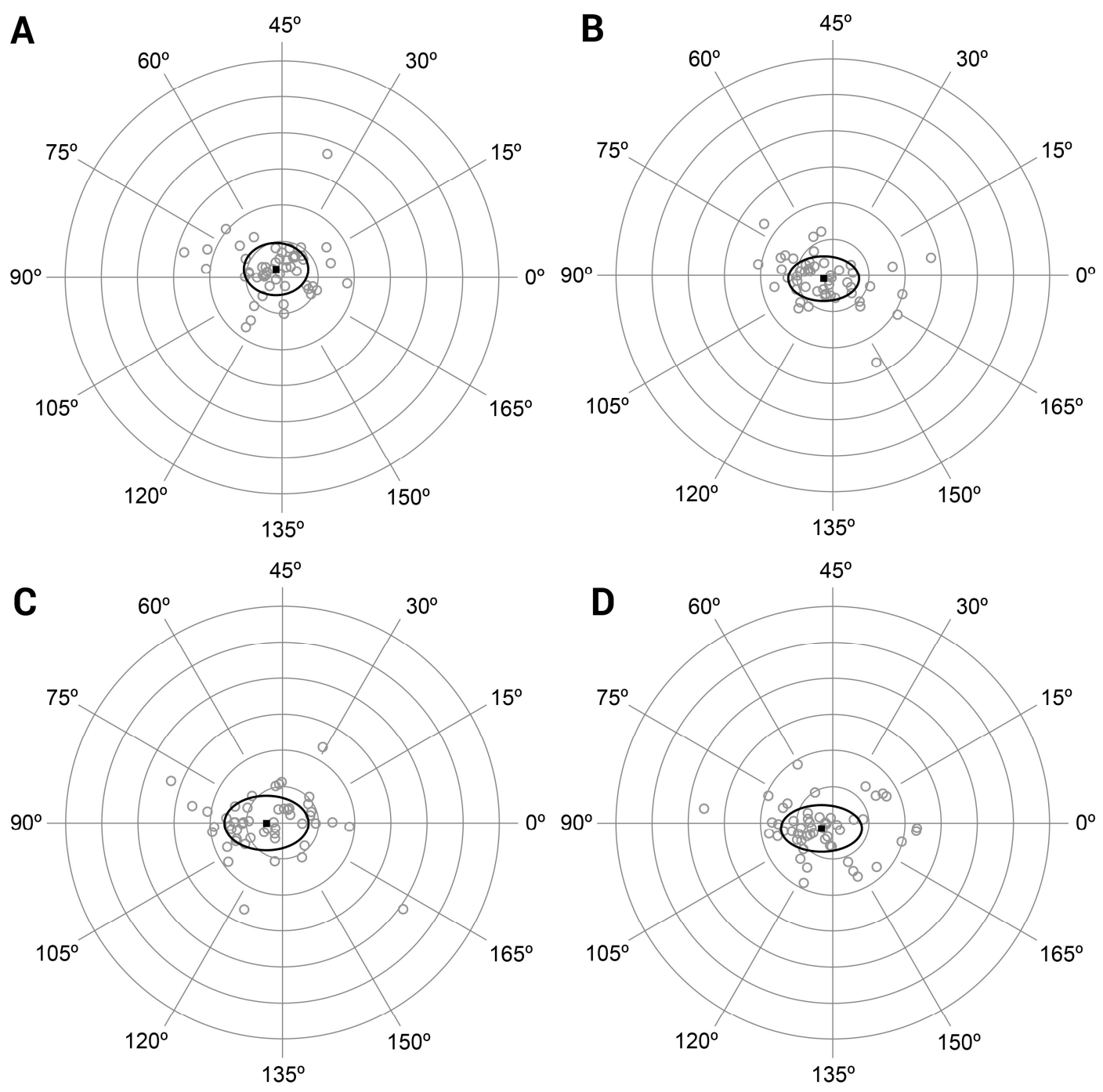
Figure 2. Correlations between the (A) $\mathrm{X}$ component from the preoperative astigmatism and the $\mathrm{X}$ component from the SIA; (B) Y component from the preoperative astigmatism and $\mathrm{Y}$ component from the SIA.
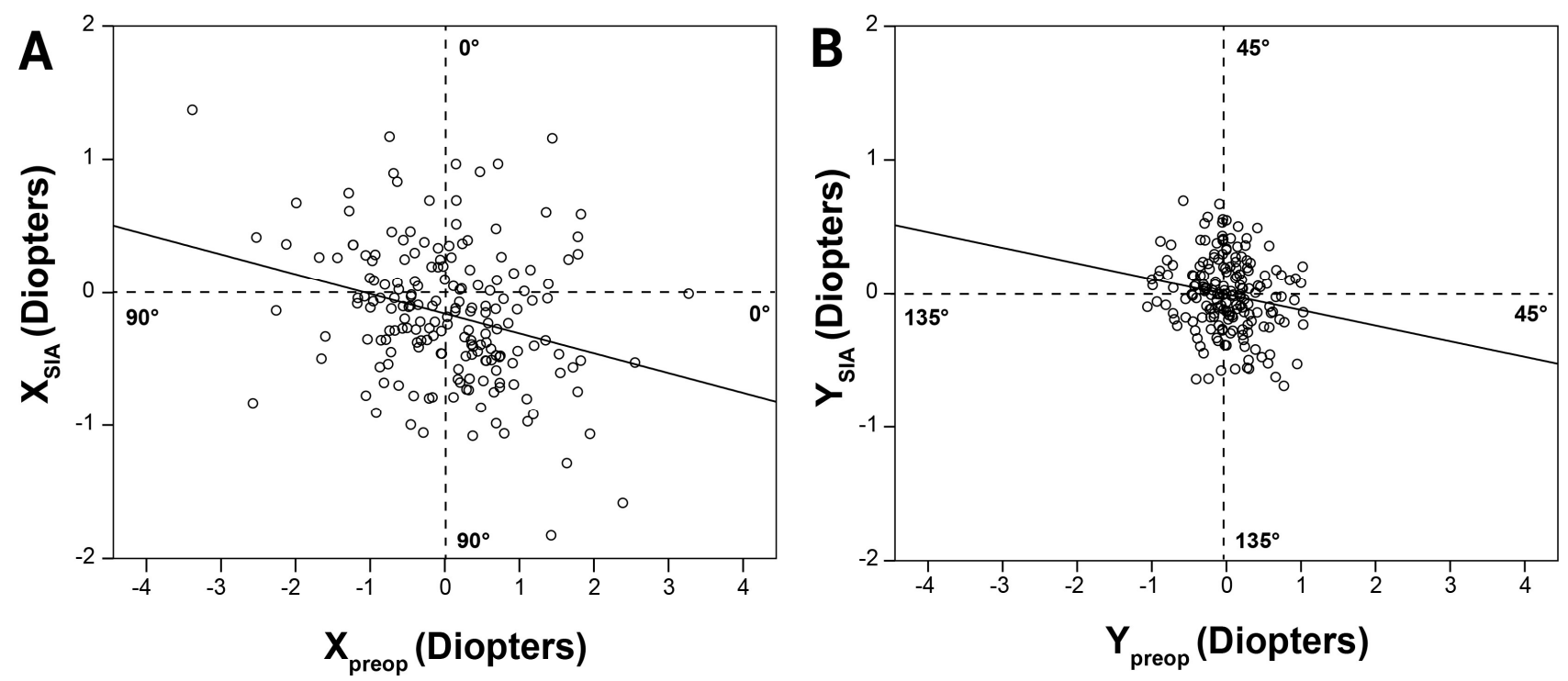

Figure 3. Difference between the manifest postoperative astigmatism and (A) the postoperative astigmatism predicted with the addition of the median SIA $\left(0.18 \mathrm{D} @ 90^{\circ}\right)$ and (B) the postoperative astigmatism predicted with the addition the SIA obtained from the model. Sector steps corresponds to 0.5 diopter.
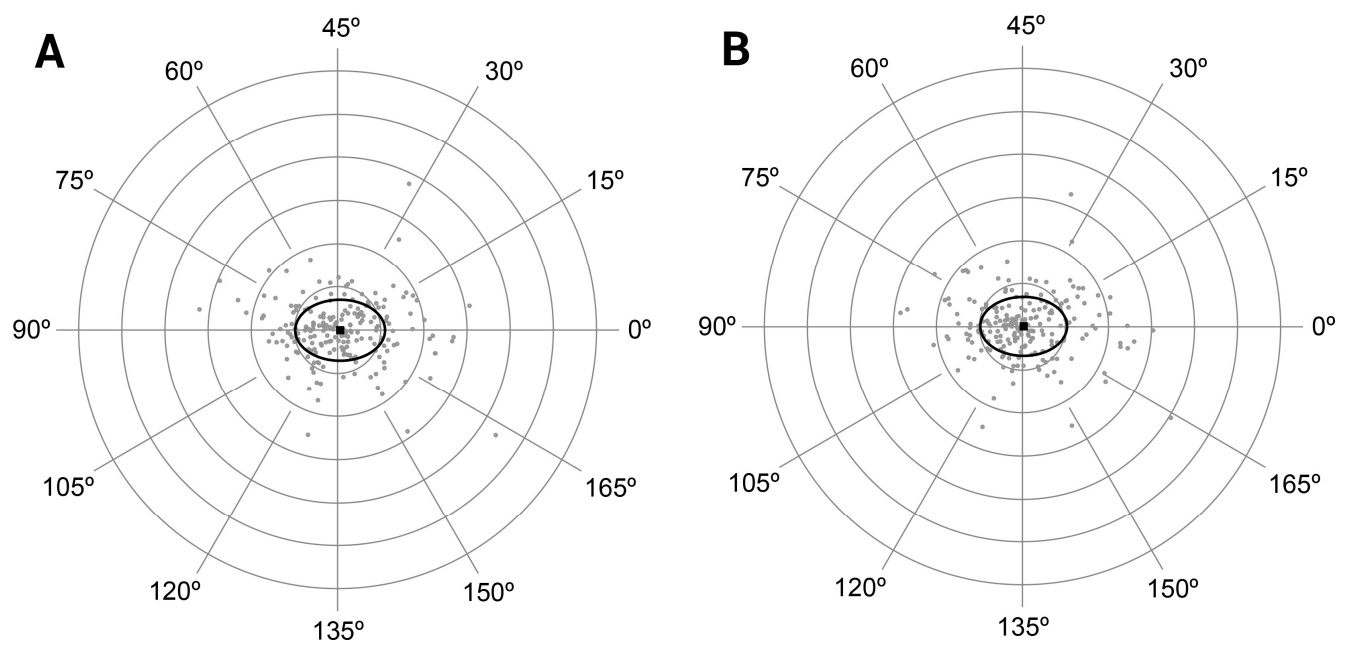
Prediction of surgically induced astigmatism 